\title{
Raising our voice in Brussels
}

\section{W. Puhl}

(C) EFORT 2011

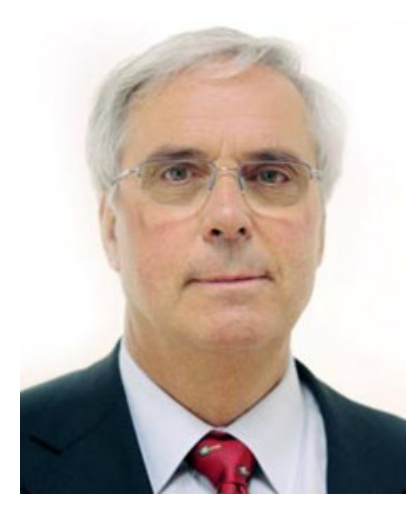

In these austerity-driven times, the dichotomy between the complicated cases we see on a daily basis in our orthopaedic practices, and the low-cost, speedy outcome the health service is pushing us to aim for, could become broader than it is already. So how can we reduce the gap between what is the current reality and what it should be in European orthopaedics? EFORT's European Union (EU) Task Force is working on this very question.

Today, $70 \%$ of new legislation in the EU is designed and decided in Brussels, with the European Commission, European Parliament and Council of the EU the key institutions at the heart of these changes. In public health, the EU shares competences with its Member States: whilst each Member State retains sole power to legislate in the area of health, the EU provides a supporting role by

\section{W. Puhl $(\bowtie)$}

Orthopädische Spezialklinik Oberstdorf,

Trettachstrasse 16,

87561 Oberstdorf, Germany

e-mail: wolfhart.puhl@me.com strongly encouraging cooperation between Member States, establishing guidance and exchanging best practices. The EU seeks, in particular, to ensure equity of care and looks to set minimum standards to be upheld across Europe for key disease areas (e.g. chronic diseases). In this context, the European institutions welcome the input of professional, industry and patient representatives, and seek in many cases to work through partnerships. This stakeholder input takes place in the Brussels environment through advocacy to draw attention to an issue, or to win the support of key constituencies in order to influence policies and spending, and bring about change. To this end, thousands of European organisations have been established in Brussels to leverage their profile and lobby for their cause. Currently, there are several well-established organisations who have been active for many years in Brussels, driving the debate on musculoskeletal health, for example, by organising highlevel policy events involving EU policy makers in charge of shaping the legislation in this field and in public health.

Since September 2010, EFORT has been driving — with the support of the European public affairs agency Interel-a campaign of policy activities at the EU level to raise the profile of the organisation among policy makers and other key organisations, and become a partner in the health debate on musculoskeletal health and our ageing population in Europe. It has been long known to the orthopaedic community that the number of Europeans aged $65+$ will almost double over the next 50 years, from 85 million in 2008 to 151 million in 2060, but finally now policy makers at the EU level have taken notice of this significant shift. This trend represents a challenge for public authorities, policy makers, businesses and the non-profit sector; especially as it comes at a time of steady decline in the number of care workers and increases in the availability of 
healthcare products and services (Draft Strategic Implementation Plan for the European Innovation Partnership on Active and Healthy Ageing).

Keeping the elderly healthy is crucial in addressing these major challenges. The European Innovation Partnership (EIP) seeks to address such societal challenges through innovation and technology. ${ }^{1}$ The first EIP pilot project was launched on 26 November 2010, on "Active and Healthy Ageing", with a public consultation to which EFORT contributed. The European Commission received 524 answers and presented a report summarising the key findings, in which it presents the EFORT example on Registries for Hip and Knee Arthroplasty. This indicated the Commission recognition of the value of national registers in improving the quality of care of patients with hip or knee joint replacement. EFORT further positioned the organisation as a keen contributor to the debate on active and healthy ageing and organised its very first EU Political Symposium on "Active Ageing and Musculoskeletal Conditions" in Copenhagen last June. The symposium brought together officials from the World Health Organization (WHO), the European Commission, the European Parliament and key opinion leaders in musculoskeletal health, and addressed the need for musculoskeletal disorders to become a key European Union priority in the context of an increasing ageing population and to examine the role of the musculoskeletal community in contributing to healthy ageing.

Following the success of the event, EFORT was invited to take part in the stakeholders workshops organised by the European Commission on the "Innovation Partnership on
Active and Health Ageing", during which further best-case practices in the field of Registries for Hip and Knee Arthroplasty were submitted. The Innovation Partnership Steering Committee has now adopted the Strategic Implementation Plan (SIP) for Active and Healthy Ageing, and thanks to advocacy work of EFFORT, they have identified as one of the key priority actions: "The Prevention of Falls and Support of Early Diagnosis for Older People".

These strides in policy which will improve musculoskeletal health in Europe are the result of EFORT's work and constant commitment to the debate on active and healthy ageing. The opportunity is now open for EFORT to be part of the task force, which will be set up in 2012, to put in place operational programmes for the early diagnosis and prevention of falls in a majority of European countries. As the year 2012 has been officially adopted by the EU institution as the year of "Active Ageing and Solidarity between Generations", EFORT is now strategically placed to work in partnership with the EU institutions and relevant groups to raise the profile of the orthopaedic and trauma profession at the European level and to demonstrate the role of the profession in helping reduce the economic and social burden of musculoskeletal conditions on society. In the long term, this will also ensure that the discipline receives adequate attention for its significant role in public health and, therefore, adequate funding for research and innovation.

EFORT will continue to explore opportunities to translate policy opportunities into professional opportunities, and to advocate for the creation of an ideal playing field in which to practice medicine and any given speciality.

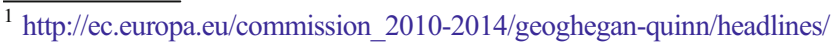
documents/com-2010-546-final_en.pdf 